\title{
A Comprehensive Energy Optimized Operation Strategy Based on Energy Storage Model
}

\author{
Bi-yan MA ${ }^{\text {a }}{ }^{1}$, Xiao-dan ZHANG ${ }^{\text {a }}$ and Hao-jie ZHOU ${ }^{\text {a }}$ \\ ${ }^{a}$ Guangzhou Dongfang Dianke Automation Co. Ltd., Guangzhou 510000, China
}

\begin{abstract}
The unified modeling of distributed resources in comprehensive energy parks is the basis to achieving energy scheduling. This article first analyzed the key modeling elements of the energy storage model, the conversion of central air conditioning and ice storage to the energy storage model was completed. Finally, based on the unified energy storage model in combination with the time-of-use electricity prices and load conditions of the park, the local economic operation strategy of distributed resources was realized. The energy storage model and local operation strategy were used as the edge computing of the energy management gateway, which realized the real-time status monitoring and economic operation scheduling of the comprehensive energies. This study provides local solutions for the economic operation of comprehensive energy parks.
\end{abstract}

Keywords. Energy storage model; ice storage; central air conditioning

\section{Introduction}

In recent years, the development of distributed energy has grown rapidly. The comprehensive energy system has a wealth of power load control methods such as energy storage, demand side response, and flexible load, and thus can quickly respond to the peak and frequency modulation services of the grid. However, when there is no grid dispatching curve, how to make comprehensive energy operate safely and economically locally according to the real-time operation of the grid, and maximize the benefits of multiple energy complements, has become an urgent issue to be solved [1-3]. Based on the study of the key elements of energy storage, ice storage and central air conditioning, this paper establishes a unified energy storage charging and discharging model, aiming to model the conversion of ice storage and central air conditioning to energy storage. corresponding local economic operation strategies are formulated to realize the unified scheduling and the same local operation strategy implementation of a variety of different distributed resources, which provides flexible solutions for the control of local economic operation for parks with distributed resources.

\footnotetext{
${ }^{1}$ Corresponding Author, Bi-yan MA (1982), Guangzhou Dongfang Dianke Automation Co. Ltd., Guangzhou 510000, China; E-mail: 934412643@qq.com.
} 


\section{Energy Storage Model}

The energy storage model is a model built for battery system-type energy storage charging and discharging stations. The main elements for modeling the battery system energy storage are:

Transformer capacity S. The PCS system in the energy storage station continuously monitors, using 0.95 as a reference value, the rated active power and maximum charging current of the energy storage station are calculated to be

$$
\begin{aligned}
P_{0} & =0.95 * S \\
I_{\max } & =\frac{P_{0}}{3 * U_{N}}
\end{aligned}
$$

where $P_{0}$ is the rated active power of the energy storage station, $\mathrm{S}$ is the transformer capacity, $U_{N}$ is the rated voltage of the transformer, and $I_{\max }$ is the maximum charging current of the energy storage station.

Total battery system capacity $\mathrm{C}$. The total capacity of the battery system is a fixed parameter in the model.

Current SOC of the battery system. The battery system SOC is an important parameter of its energy storage status. The Equation of battery SOC at time $t$ is

$$
\operatorname{sOC}(\mathrm{t})=\operatorname{soC}(\mathrm{t}-\Delta \mathrm{t}) \frac{\int_{0}^{\Delta t} i d t}{C}
$$

where $\mathrm{C}$ is the total capacity of the battery system, $\mathrm{SOC}(\mathrm{t})$ is the SOC value of the battery at time $t$, and $i$ is the operating current value of the battery at time $(t-\Delta t)$.

SOC threshold and SOH. To prevent the battery system from overcharging and overdischarging, thresholds for entering discharge $S O C_{\text {start_discharge }}$ and stopping discharge $S O C_{\text {discharge_limit }}$ are set. The equation for battery system $\mathrm{SOH}$ estimation is

$$
\mathrm{SOH}=\frac{S O C-S O C_{\text {discharge_limit }}}{100-S O C_{\text {discharge_limit }}}
$$

\section{Ice Storage to Energy Storage Model}

The ice storage air conditioner uses the low load power of power grid to make ice and store it in the ice storage device, and release the stored cold energy during the peak load period of the power grid to reduce the power load of air conditioning and the installed capacity of the air conditioning system during the peak time of the grid. The energystorage-like behavior of ice storage can be modeled as an energy storage system:

\subsection{Total Capacity of The Energy Storage System C}

The maximum cold storage capacity of the ice storage system can be equivalent to the total capacity $\mathrm{C}$ of the energy storage system. 


\subsection{SOC Model}

SOC of battery describes the state of charge, the SOC model conversion can be realized from the current remaining ice volume (SC_left) and the total cold storage capacity (SC) of the ice storage system. The conversion Equation is as follows:

$$
S O C=\frac{\text { SC_left }}{S C}
$$

\subsection{Maximum Charging Power $P_{-}$max}

The maximum charging power refers to the maximum power that the current energy storage system can absorb from the grid. In the ice storage system, the power drawn from the grid can be composed of two parts, one is the power drawn by the cooling load, and the other is the power drawn by the ice making. Therefore, according to the demand of the cooling load and the current remaining ice volume, the following situations can be listed:

1. Current cooling load $>0$

a) When current remaining ice capacity <cold storage capacity, the maximum charging power $\mathrm{P}_{-} \max$ is the sum of ice making power and cooling power

$$
\mathrm{P} \_\max =\mathrm{P} \_\mathrm{ice}+\min \left(\mathrm{P} \_ \text {cool, } \mathrm{P}_{-} \mathrm{QR}\right) * \mathrm{~F}_{-} \mathrm{TR}
$$

where $\mathrm{P}_{-}$ice is the ice making power, $\mathrm{P}_{-}$cool is the cooling power, $\mathrm{P} \_\mathrm{QR}$ is the current cooling load, and $F_{-}$TR is the cooling ton conversion coefficient. $1 \overline{\mathrm{US}}$ cooling ton $=$ 3024 kilocalories per hour $(\mathrm{kcal} / \mathrm{h})=3.517$ kilowatts $(\mathrm{kw})$.

b) Otherwise, when the current remaining ice capacity= cold storage capacity, the maximum charging power $\mathrm{P}_{-}$max is just the cooling power

$$
\mathrm{P}_{-} \max =\min \left(\mathrm{P}_{-} \text {cool, } \mathrm{P}_{-} \mathrm{QR}\right) * \mathrm{~F}_{-} \mathrm{TR}
$$

where $\mathrm{P}_{-}$cool is the cooling capacity, $\mathrm{P}_{-} \mathrm{QR}$ is the current cooling load, and $\mathrm{F}_{-} \mathrm{TR}$ is the conversion coefficient of the cooling ton, as above.

2. No cooling load (e.g. no need for ice storage in winter)

There is no need for ice making and cooling, and therefore the maximum charging power $\mathrm{P}_{-} \max$ is 0

$$
\text { P_max }=0
$$

\subsection{Maximum Discharge Power P max}

The maximum discharge power refers to the maximum power that the current energy storage system can deliver to the grid. Since ice storage does not have the ability to transmit electrical energy, the current maximum reduction of power drawn from the grid can be equivalent to the maximum discharge power. The electricity consumption of the ice storage system mainly includes ice making and refrigeration. According to the current electricity consumption, they can be calculated as follows:

1. Remaining ice volume $>0$

Since ice storage has remaining ice, the cooling load can be provided completely by ice melting. Therefore, the current electricity used for ice making and cooling can be converted into discharge power. The calculation equation is as follows: 


$$
\text { P_max }=\text { Sts_ice*P_ice }+ \text { Sts_cool*P_cool*F_TR }
$$

where $\mathrm{P}_{-} \max$ is the discharge power, Sts_ice is the state of the ice maker before discharging, $\mathrm{P}$ ice is the ice making power, Sts_cool is the cooling state before discharging, $\mathrm{P}_{-}$cool is the refrigeration capacity, $\mathrm{F}_{-}{ }_{-} \mathrm{TR}$ is the conversion factor of the cooling ton, the same as above.

2. Remaining ice volume $=0$

Since the remaining ice volume of the ice storage system is 0 , the current cooling load cannot be provided by melting ice, that is, this part of the power cannot be reduced. Therefore, only the current electric power used for ice making can be converted into discharge power. The calculation equation is as follows:

$$
\text { P_max }=\text { Sts_ice*P_ice }
$$

where $\mathrm{P}_{-}$max is the discharge power, Sts_ice is the state of the ice maker before discharging, and $\mathrm{P}_{-}$ice is the ice making power.

\section{Central Air Conditioning to Energy Storage Model}

The air-conditioning system has a certain heat storage capacity, load adjustment can be carried out with fast response speed and the great potential. The indoor temperature range is recorded as [Tmin, Tmax], when the room temperature of the air-conditioned room is less than Tmax, turning off the air conditioner for a short time or increasing its set temperature can reduce the overall load level of the air-conditioning cluster [4-5]. Therefore, when the room temperature is lower than Tmax, it can be considered that the air-conditioned room has stored part of the cooling capacity. Based on this idea, the energy storage model of a single air conditioner is established.

\subsection{Total Capacity of Energy Storage System}

The energy storage characteristics of central air conditioning reflect the load regulation ability conferred by the indoor temperature range. Therefore, the total energy storage capacity can be equivalent to the equivalent energy stored between the maximum room temperature and the minimum room temperature, as shown in Eq. (11):

$$
\text { Capacity }=\mathrm{C}(\mathrm{Tmax}-\mathrm{Tmin}) / \eta
$$

where Capacity is the total capacity of energy storage, $\mathrm{C}$ is the equivalent heat capacity of the air-conditioned room, indicating the amount of heat absorbed or released for every $1^{\circ} \mathrm{C}$ change in temperature. A value of $1080 \mathrm{~kJ} /{ }^{\circ} \mathrm{C}$ is taken in this model. $\eta=3$ is the airconditioning energy efficiency ratio.

\subsection{SOC}

SOC equation is: $\quad \mathrm{SOC}=\frac{\mathrm{C}(\mathrm{Tmax}-\mathrm{Tin}) / \eta}{C_{\text {apacity }}}=\frac{(\mathrm{Tmax}-\mathrm{Tin})}{(\mathrm{Tmax}-\mathrm{Tmin})}$

where Tin is the current indoor temperature. 


\subsection{Maximum Charge and Discharge Power P_max}

1. Maximum charge power

The rated power of the central air conditioning $\mathrm{P} \_$max can be equivalent to the maximum charging power Prate, namely

2. Maximum discharge power

$$
\text { P_max }=\text { Prate }
$$

The discharge power P_max formula is as follows:

$$
\mathrm{P}_{-} \max =\frac{T_{\text {out }}(t)-T_{\text {in }}(t)}{\eta R}
$$

where $T_{\text {out }}(t)$ is the outdoor temperature, and $T_{\text {in }}(t)$ is the indoor temperature.

\subsection{SOC Threshold}

The maximum chargeable SOC (SOCmax) and the minimum dischargeable SOC (SOCmin) thresholds are defined, such that when the room temperature reaches the thresholds, the energy storage will stop, and normal operation starts (Figure 1).

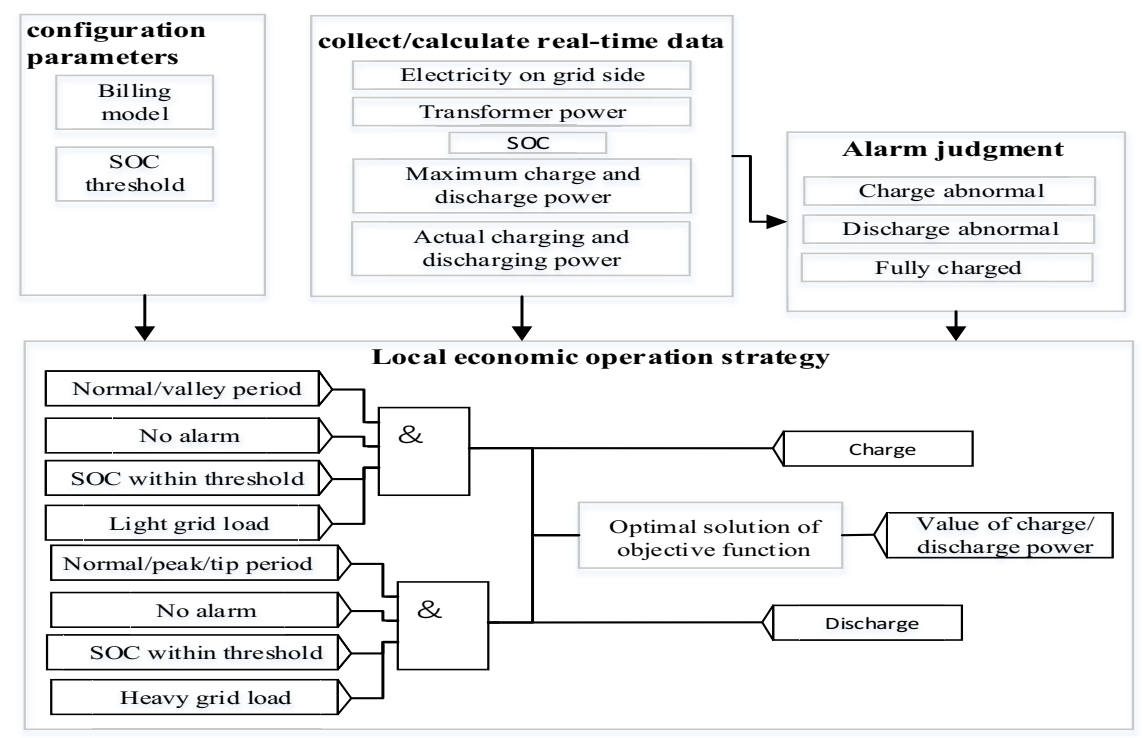

Figure 1. Logic diagram of software framework.

\section{Energy Storage Local Economic Operation Strategies and Model Simulation}

\subsection{Energy Storage Local Economic Operation Strategies}

After ice storage and central air conditioning are converted to energy storage model, energy storage, ice storage and central air conditioning can all share the same economic operation strategy to perform local optimization scheduling. Factors affecting the economic operation of energy storage mainly include time-of-use electricity prices, 
current load of the park, etc. When the electricity price is in the valley, the energy is stored by turning on energy storage charging, starting ice making, and central air conditioning (or adjusting temperature). When it is at the peak price of electricity, the power drawn from the grid is reduced by discharging the energy storage, melting ice, turning off central air conditioning (or temperature adjustment), etc., thereby forming peak-to-valley arbitrage. When the power grid is in a normal period, the charging and discharging control needs to be dynamically determined according to the current park load situation, battery energy storage situation, and whether the next period type is peak period or valley period.

Device configuration parameters, equivalent calculated values of the energy storage model, and the alarm status of the energy storage model are used as the entry status of the local economic strategy. When there is no alarm in the valley period, enter the charge mode. When there is no alarm in the peak period, enter the discharge mode. Charging and discharging modes are flexibly switched during normal hours according to the current load level of the park. The charging and discharging power is solved by the optimal function method.

The energy storage model conversion algorithm is run in the distributed energy gateway as edge computing, and the charge state of various distributed energy sources is configured according to the load situation of the park. The feasibility of the algorithm is verified by running in real time. The distributed resources in the simulated park are as follows: Load 1 and Load 2 are energy storage warehouse loads, Load 3 is central air conditioning, and Load 4 is ice storage.

\subsection{Model Conversion}

\subsubsection{Model Conversion of Ice Storage}

Perform energy storage modeling on ice storage. The configuration parameters are shown in Table 1.

Table 1. configuration data of the ice storage model.

\begin{tabular}{llll}
\hline Name & desp & Unit & Meaning \\
\hline ice_cool_storage & Cold storage capacity & Rth & \\
\hline ice_cooling_capacity & Refrigeration capacity & $\mathrm{Rt}$ & $\begin{array}{l}\text { Used to convert the maximum } \\
\text { refrigerator power }\end{array}$ \\
\hline ice_P_making_ice & Ice making power & $\mathrm{kw}$ & $\begin{array}{l}\text { Used to convert the operating } \\
\text { power of the ice maker }\end{array}$ \\
\hline ice_max_melting & Maximum melting ice capacity & $\mathrm{Rt}$ & \\
\hline
\end{tabular}

Table 2. Real-time data of the ice storage model.

\begin{tabular}{llll}
\hline Name & Desp & Unit & Meaning \\
\hline left_storage & Current remaining ice & Rth & \\
\hline cooling_load & Current cooling load & Rt & Current demand of cooling capacity \\
\hline ice_sts & Ice maker status & & Current status: open/close \\
\hline cooling_sts & Refrigerator status & & Current status: open/close \\
\hline cooling_output & Cooling capacity & Rt & \\
\hline melting & Melted ice capacity & Rt & \\
\hline soc & SOC & $\%$ & \\
\hline max_power & Maximum charge/discharge power & $\mathrm{kw}$ & \\
\hline
\end{tabular}


Collect real-time data of ice storage, and calculate the equivalent SOC and maximum charge and discharge power in real time (Table 2). The simulation configuration data are entered, with the cold storage capacity, refrigeration capacity, ice making power, and maximum ice melting capacity being $60 \mathrm{Rth}, 10 \mathrm{Rt}, 15 \mathrm{kw}$, and 10 $\mathrm{Rt}$, respectively. The simulation real-time data are as follows: current remaining ice capacity 30 Rth, current cooling load 10 Rt, ice maker status: 1, and refrigerator status 1 . The simulation enters the valley period, the SOC calculated by the gateway is $50 \%$, and the maximum charging power is $50.17 \mathrm{kw}$. The real-time values of the database are shown in Figure 2.

\begin{tabular}{|l|r|r|r|}
\hline name & value & change_time_s & change_time_ms \\
\hline load4_left_storage & 30 & 0 & 0 \\
\hline load4_cooling_load & 20 & 0 & 0 \\
\hline load4_echeduling_power & 50.17 & 1616780870 & 313 \\
\hline load4_power & 35.1 & 0 & 0 \\
\hline load4_ice_sts & 1 & 0 & 0 \\
\hline load4_cooling_sts & 1 & 1616778245 & 0 \\
\hline load4_ice_ctrl & 1 & 1616780878 & 202 \\
\hline load4_cooling_output & 10 & 1616780878 & 206 \\
\hline load4_melting & 10 & 1616780865 & 208 \\
\hline load4_soc & 50 & 1616780865 & 770 \\
\hline load4_max_power & 50.17 & & 774 \\
\hline
\end{tabular}

Figure 2. Calculated value of load 4 during the valley period.

Notes: Database description: load4_echeduling power is the charge and discharge power value of real-time scheduling. The value is positive for charging power, and negative for discharging power. The sum of the charging and discharging power of each distributed resource load should not be greater than maximum charging and discharging power value of the PCS. The maximum charge and discharge power of the park is configured to be $100 \mathrm{kw}$. In this simulation, the real-time scheduling of ice storage charging power is $50.17 \mathrm{kw}$, which does not exceed the maximum charging and discharging power of the park. Therefore, the real-time scheduling charge and discharge power value is $50.17 \mathrm{kw}$, and the ice making is controlled to be turned on, and the load4_ice_ctrl value is 1 . The "change_time_s" column in the database is the UTC timestamp when the database data is updated.

The simulated real-time data are as follows: current remaining ice volume 45 Rth, current cooling load $10 \mathrm{Rt}$, ice maker status 1 , and refrigerator status 1 .

The simulation enters the peak period. The SOC calculated by the gateway is $75 \%$, the maximum discharge power is $50.17 \mathrm{kw}$, and the real-time scheduling load discharge load4_echeduling_power is $-50.17 \mathrm{~kW}$. And the control to shut down the ice making function load4_ice_ctrl value is 0 . The real-time value of the database is shown in Figure 3.

\begin{tabular}{|l|r|r|r|}
\hline name & value & change_time_s & change_time_ms \\
\hline load4_left_storage & 45 & 0 & 0 \\
\hline load4_cooling_load & 10 & 0 & 0 \\
\hline load4_echeduling_power & -50.17 & 1616830214 & 241 \\
\hline load4_power & 35.1 & 0 & 0 \\
\hline load4_ice_sts & 1 & 0 & 0 \\
\hline load4_cooling_sts & 1 & 0 & 0 \\
\hline load4_ice_ctrl & 0 & 1616830266 & 131 \\
\hline load4_cooling_output & 10 & 1616781956 & 147 \\
\hline load4_melting & 0.000001 & 1616781956 & 149 \\
\hline load4_soc & 75 & 1616830212 & 377 \\
- load4_max_power & 50.17 & 1616830212 & 659
\end{tabular}

Figure 3. Calculated value of load 4 during peak period. 


\subsubsection{Central Air Conditioning Model Conversion}

Perform energy storage modeling for central air conditioning. The configuration parameters are shown in Table 3:

Table 3. Central air conditioning model configuration data.

\begin{tabular}{lllll}
\hline Name & Desp & Value & Unit & Meaning \\
\hline AC Capacity & Capacity & \multicolumn{2}{c}{$\mathrm{kJ}$} & \\
\hline AC_R & $\begin{array}{l}\text { Equivalent thermal resistance of } \\
\text { air-conditioned room }\end{array}$ & $\begin{array}{l}{ }^{\circ} \mathrm{C} / \mathrm{k} \\
\mathrm{W}\end{array}$ & \\
\hline AC C & Equivalent heat capacity & 1080 & $\mathrm{~kJ} /{ }^{\circ} \mathrm{C}$ & \\
\hline AC_eta & $\begin{array}{l}\text { Air conditioning energy } \\
\text { efficiency ratio }\end{array}$ & 3 & & $\eta$ \\
\hline AC_Tmin & Minimum temperature & 24 & ${ }^{\circ} \mathrm{C}$ & \\
\hline AC_Tmax & Maximum temperature & 28 & ${ }^{\circ} \mathrm{C}$ & \\
\hline AC_SOCmax & Maximum charge SOC & 90 & & $\begin{array}{l}\text { Cannot charge after } \\
\text { reaches this value }\end{array}$ \\
\hline AC_SOCmin & Minimum discharge SOC & 10 & & $\begin{array}{l}\text { Cannot discharge after SOC is } \\
\text { less than this value }\end{array}$ \\
\hline AC_P_rate & Rated power of air conditioner & 3 & $\mathrm{kw}$ & $\begin{array}{l}\text { Use this power as the charging } \\
\text { power when charging }\end{array}$ \\
\hline
\end{tabular}

The real-time data of central air conditioning were collected, and the equivalent SOC and maximum charge and discharge power in real time were calculated. The real-time data table is shown in Table 4.

Table 4. Real-time data of central air conditioning model.

\begin{tabular}{llll}
\hline Name & Desp & Unit & Meaning \\
\hline soc & Remaining capacity & & \\
\hline Tin & Indoor temperature & ${ }^{\circ} \mathrm{C}$ \\
\hline Tout & Outdoor temperature & ${ }^{\circ} \mathrm{C}$ \\
\hline max_Power & Maximum charge/discharge power & $\mathrm{Kw}$ \\
\hline fault & Alarm status & \\
\hline
\end{tabular}

The simulation data are as follows: configure the cold storage capacity to be $136 \mathrm{~kJ}$, the equivalent thermal resistance of the air-conditioned room is $10.6^{\circ} \mathrm{C} / \mathrm{kW}$, and the equivalent thermal capacity is $1080 \mathrm{~kJ} /{ }^{\circ} \mathrm{C}$. The energy efficiency ratio of the air conditioner is 3 , the minimum temperature is set to $24^{\circ} \mathrm{C}$, and the maximum temperature is set to $28^{\circ} \mathrm{C}$. The maximum charge SOC is $90 \%$, the minimum discharge $\mathrm{SOC}$ is $10 \%$, and the rated power of the air conditioner is $3 \mathrm{kw}$.The simulated real-time data are as shown in Figure 4: indoor temperature $26.3^{\circ} \mathrm{C}$, outdoor temperature $30^{\circ} \mathrm{C}$. Simulation enters the valley period. The SOC calculated by the gateway is $42 \%$, and the maximum charging power is $3 \mathrm{kw}$ (rated power of air conditioner).

\begin{tabular}{|l|r|r|r|}
\hline name & value & change_time_s & change_time_ms \\
\hline load3_soc & 42 & 1616778224 & 760 \\
\hline load3_Tin & 26.3 & 0 & 0 \\
load3_Tout & 30 & 0 & 0 \\
\hline load3_max_power & 3 & 1616778245 & 171 \\
\hline load3_fault & 0 & 0 & 0 \\
\hline load3_echeduling_power & 3 & 1616778245 & 198
\end{tabular}

Figure 4 Calculated value of load 3 during valley period.

Notes: Database description is the same as above. The simulated charging power load3_echeduling_power for real-time scheduling of central air conditioning is $3 \mathrm{kw}$. The "change_time_s" column in the database is the UTC timestamp when the database data is updated. 
The real-time database is as shown in Figure 5. Real-time data changes: Indoor temperature is $25^{\circ} \mathrm{C}$, outdoor temperature is $30^{\circ} \mathrm{C}$. The simulation enters the peak period, the SOC calculated by the gateway is $75 \%$, and the maximum discharge power is $0.157233 \mathrm{kw}$.

\begin{tabular}{l|r|r|r|} 
name & value & change_time_s & change_time_ms \\
\hline load3_soc & 75 & 1616824600 & 62 \\
\hline load3_Tin & 25 & 0 & 0 \\
\hline load3_Tout & 30 & 0 & 0 \\
\hline load3_max_power & 0.157233 & 1616824600 & 65 \\
\hline load3_fault & 0 & 0 & 0 \\
load3_echeduling_power & -0.157233 & 1616824600 & 135
\end{tabular}

Figure 5. Calculated value of load 3 during peak period.

Notes: Database description is the same as above. The discharge power load3_echeduling_power for real-time scheduling of central air conditioning is $-0.157233 \mathrm{kw}$. Negative number represents discharge. The "change_time_s" column in the database is the UTC timestamp when the database data is updated.

\subsection{Charge and Discharge Control}

The billing model of Guangdong area is used. That is, " $0-8$ o'clock, valley period; $8-14$ o'clock, normal period; 14-17 o'clock, peak period; 17-19 o'clock normal period, 19-22 o'clock, peak period; 22-0 o'clock, normal period". Combining with the spontaneous or self-consumption situation of plants and stations, priority is given to ensuring selfconsumption, followed by peak-to-valley arbitrage to realize charge and discharge control. The billing model database configuration is shown in Figure 6.

\begin{tabular}{|c|c|c|}
\hline id & name & value \\
\hline 13 & rate1_time & o \\
\hline 14 & rate1_type & 4 \\
\hline 15 & rate2_time & 800 \\
\hline 16 & rate2_type & 3 \\
\hline 17 & rate3_time & 1200 \\
\hline 18 & rate3_type & 2 \\
\hline 19 & rate4_time & 1400 \\
\hline 20 & rate4_type & 3 \\
\hline 21 & rate5_time & 1500 \\
\hline 22 & rate5_type & 2 \\
\hline 23 & rate6_time & 1600 \\
\hline 24 & rate6_type & 3 \\
\hline
\end{tabular}

Figure 6. Billing model.

Notes: rate1 time is the start time of billing period 1 . Rate1_type is the type of charging period 1 , where 0 is the tip period, 1 is the peak period, 2 is the normal period, and 3 is the valley period, and so on for other periods.

Simulation enters the valley period, and the SOC is not full. After the gateway executes the program, it outputs the charging status and dispatches various distributed resource loads into the charging status. Figure 7 is a screenshot of the charge/discharge $\log$ of the device. The simulation enters the peak period, and the SOC is greater than the set value of termination of discharge. After the gateway executes the program, it outputs the discharge status and schedules various distributed resource loads to enter the discharge status. Figure 8 is a screenshot of the charge/discharge log of the device.

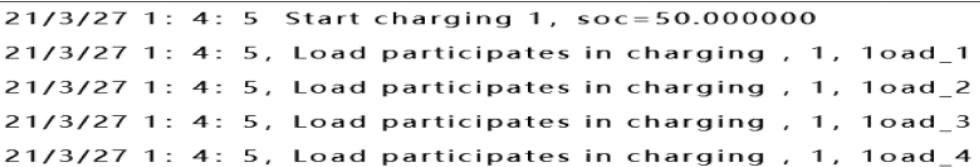

Figure 7. Charging log during valley hours. 


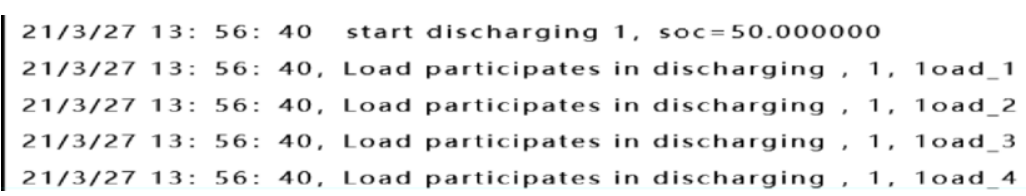

Figure 8. Discharge log during peak hours.

\section{Conclusion}

This article first summarized the key elements of energy storage station modeling, and then analyzed the operating modes of ice storage and central air conditioning. Then the operating parameters of ice storage and central air conditioning were converted to the energy storage model elements to form a unified distributed energy model with energy storage as the main model. On the basis of unified modeling, according to the time-ofuse electricity price, the current load of the park and other influencing factors, the charging and discharging control strategy of the local economic operation of the park's distributed resources was formulated. The model of energy storage, ice storage, central air conditioning, and local operation strategies were deployed as edge computing applications to the energy management gateway. After simulation calculation, the following conclusions are drawn: the energy storage model of ice storage and central air conditioning can be converted in real time according to the load condition. The energy management gateway used a unified model to conveniently realize the flexible scheduling without differentiation of multiple distributed resources. It provides local solutions for the economic operation of comprehensive energy parks, improves the economic benefits of energy parks, which makes it worth promoting.

\section{Reference:}

[1] Zhang YN, He YB, Yan MY, et al. Optimal dispatch of integrated electricity-natural gas system considering demand response and dynamic natural gas flow. Automation Electric Power Syst. 2018; 42(20): 1-10.

[2] Wu M, Li ZW, Sun LJ. A model predictive overall control method for hybrid energy storage converter. Power Syst. Protection Contr. 2020; 48(21): 84-91.

[3] Wang HH, Chen JJ, Zhu T et al. Joint bidding model and algorithm of wind-storage system considering energy storage life and frequency regulation performance. Power Syst. Technol. 2021; 45(01): 208-217.

[4] Wang SX, Zhu W. Optimal scheduling of CCHP micro-grid with ice storage air-conditioning. J. Shanghai Univer. Electr. Power, 2021; 37(1): 37-43.

[5] Cheng S, Huang TL, Wai RJ. Multi-time-scale optimal scheduling of CCHP microgrid with ice-storage air-conditioning. Automation Electr. Power Syst. 2019; 43(05): 30-38. 